\title{
Color-word performance as a joint function of manifest anxiety and stimulus conflictfulness
}

\author{
KENNETH R. GAMBLE, DEPARTMENT OF PSYCHOLOGY, \\ GANNON COLLEGE, Erie, Pa. 16501
}

Performance on two color-word tests varying in the degree of conflict between word and color was studied in relation to drive level. Predictions based on $H \times D$ theory were not supported by the data. Limited evidence of a possible momentary drive factor was provided.

The Stroop Color-Word Test consists of three kinds of stimuli printed on three different cards. Card A consists of 100 color words ("red," "blue," and "green") which are printed in black ink and arranged in random order. The $S$ must read the words as quickly as possible. Card B is made up of rectangular patches of the colors red, blue, and green arranged in random order. The $S$ is required to correctly name the colors as fast as possible. Card C, the "conflict card," consists of 100 color-words ("red," "blue," and "green") printed in ink the color of which is different from the color designated by the word (e.g., the word "green" might be printed in blue ink). The task is to name as rapidly as possible the color of the ink in which the word is printed.

Color-naming time on Card $\mathrm{C}$ is always longer than colornaming time on Card B for a given $\mathrm{S}$. Also, in response to card C, Ss often giggle, become flushed, perspire, give inarticulate utterances, and, in general, show signs of stress. This has led some to infer that high levels of physiological arousal accompany performance on this task (Klein, 1964; Grand \& Segal, 1966). Champion \& Allen (1966) have shown that conflictful color-words can be used as unconditioned stimuli in conjunction with a tone to reduce latencies of a panel-pressing response. This further suggests that the arousal observed in color-word performance trials may have drive properties.

Several studies have demonstrated that high-drive conditions (other than those that may be generated by the color-word conflict) facilitate color-word performance. Calloway (1959) manipulated drive by the administration of drugs. Agnew \& Agnew (1963) and Tecce \& Happ (1964) manipulated drive by shock and threat of shock.

The present study was designed to provide information on the joint effects of drive level and stimulus conflictfulness on color-word performance. High-drive (HD) and low-drive (LD) conditions were operationalized in terms of high and low scores on the Taylor Manifest Anxiety Scale (Taylor, 1953). This measure was presumed to reflect generalized drive (D) as conceived in Hull-Spence behavior theory (Spence, 1958). Stimulus conflictfulness (operationalized below) was assumed to activate another drive component, $r_{e}$, a momentary drive factor elicited by stressful stimulation (Spence, 1958).

In line with $\mathrm{H} \times \mathrm{D}$ theory it was predicted that HD Ss would perform better than LD Ss on the color-word tasks. Also under the acute hypotheses concerning the relationship between task stress and performance (Spence, 1956; Bringmann, 1967), an interaction between drive and stimulus conflictfulness was predicted.

Subjects. Ss were 44 male, undergraduate psychology students. Ss with scores of 12 or below on the MAS were assigned to the LD group $(\mathrm{N}=22)$ and $\mathrm{Ss}$ with scores of 20 or higher were assigned to the HD group $(\mathrm{N}=22)$. One-half of the Ss in each group were randomly assigned to low-conflict (LC) and high-conflict (HC) stimulus conditions.

Stimuli. HC stimulus conditions consisted of the standard color-word test where the colors are directly related to the verbal text in which they are embedded.

The colors of the LC stimuli were, like the HC stimuli, red, blue, and green. The words in which these colors were embedded, however, were "put," "take," and "heart." Thus, in the LC condition, the words were not closely related to the color-names either in response-class or meaning. The assumption that this would provide less conflictful stimulation than the HC condition comes from a study by Klein (1964) in which it was shown that
Table 1

Mean Time to Complete Cards B + C for Five Trials under Four Combinations of Drive and Conflict

\begin{tabular}{lccccc} 
& \multicolumn{5}{c}{ Trials } \\
\cline { 2 - 6 } Drive & 1 & 2 & 3 & 4 & 5 \\
\hline HD-HC & 157.2 & 152.7 & 148.3 & 141.4 & 138.3 \\
HD-LC & 132.2 & 133.8 & 131.9 & 132.4 & 129.9 \\
LD-HC & 168.7 & 161.9 & 155.8 & 153.1 & 151.1 \\
LD-LC & 128.1 & 130.5 & 129.1 & 127.0 & 126.7 \\
\hline
\end{tabular}

interference scores (based on reading time in seconds) were significantly higher for the $\mathrm{HC}$ condition than the LC condition.

Procedure. Each $\mathrm{S}$ was given five trials. Each trial consisted of two parts. First, $\mathrm{S}$ named the color patches on Card $\mathrm{B}$ aloud and as quickly as possible. Secondly, $\mathbf{S}$ was exposed to the conflict condition (Card C). Here he was required to name the color of the ink of each colored word and completely ignore the word itself.

Fifteen seconds separated each page and each trial. Before every exposure, $E$ repeated "read as fast as you can," and before the conflict page, E said, in addition, "ignore the words."

Results. Following the lead of Calloway \& Stone (1960) and Agnew \& Agnew (1963), criterion scores were derived by arithmetically summing the time taken to complete Card B and Card $C$. The means of these measures for each of the four conditions and five trials are presented in Table 1. The data were evaluated statistically in a 2 by 2 by 5 factorial design with repeated measurements on the last factor.

Though the HD group performed consistently better than the LD group under HC condition, the trend is reversed under LC conditions. However, the main effect of drive was insignificant ( $F$ $=.27, \mathrm{df}=1 / 40$ ) as was the interaction between drive and conflict level $(\mathrm{F}=1.20, \mathrm{df}=1 / 40)$.

The main effect of conflict level was highly significant $(F=$ $12.18, \mathrm{df}=1 / 40, \mathrm{p} .01)$ as was the main effect of trials $(\mathrm{F}=$ 21.77, $\mathrm{df}=4 / 160, \mathrm{p}<.001$ ) and the Trial by Conflict interaction $(F=13.50, \mathrm{df}=4 / 160, \mathrm{p}<.001)$.

Discussion. Though the effects due to drive are consistent over trials (but not significant), a puzzling trend is shown in the HD group's superiority over the LD group under $\mathrm{HC}$ conditions but relatively inferior performance under LC conditions. This effect is strikingly similar to one observed by Wright, Gescheider, \& Battig (1963) in reference to inverted alphabet-printing tasks of varying difficulty levels. Neither result is interpretable in terms of general drive theory.

The divergence of these results from other studies showing a facilitative effect of high-drive on color-word performance may be explained by the inability of the MAS to discriminate the critical drive factors involved in color-word performance. It is interesting that where drive-level has been shown to influence color-word behavior, drive-level was manipulated rather than assessed (Calloway, 1959; Agnew \& Agnew, 1963; Tecce \& Happ, 1964).

Since neither the effect of drive nor the Drive by Conflict interaction was significant, these results have no bearing on the acute hypothesis of emotionally based drive.

The significant effect of stimulus conflictfulness confirms the differential difficulty of the stimulus items used in the HC and LC conditions. The highly significant Conflict by Trial interaction shows that performance changes with practice are greater under HC conditions than under LC conditions. Tentatively this interaction can be attributed to the differential momentary drive $\left(\mathrm{r}_{e}\right)$ stimulated by the two conflict conditions. Then, under the $\mathrm{H} \times \mathrm{D}$ hypothesis, this interaction is predictable. Further exploration of this factor is warranted.

\section{REFERENCES}

AGNEW, N. \& AGNEW, M. Drive level effects on tasks of narrow and broad attention. Quart. J. exp. Psychol, 1963, 15, 58-62.

BRINGMANN, W. G. A test of the chronic-acute hypothesis in semantic GSR conditioning. Psychon. Sci, 1967, 7, 349-350. 
CALLOWAY, E. The influence of amobarbital (amylobarbitone) and methamphetamine on the focus of attention. J. ment. Sci., 1959, 105, 382-392.

CALLOWAY, E. \& STONE, G. Re-evaluating focus of attention. In I. L. Vhr and J. G. Miller (Eds.), Drugs and behavior. New York: Wiley, 1960.

CHAMPION, R. A. \& ALLEN, G. An acquired drive based on conflict. Amer. J. Psychol, 1966, 79, 111-115.

GRAND, S. \& SEGAL, S. Recovery in the absence of recall: an investigation of color-word interference. $J$. exp. Psychol., 1966, 72, 138-144.

KLEIN, G. S. Semantic power measured through the interference of words with color-naming. Amer. J. Psychol., 1964, 77, 576-588.

SPENCE, K. W. Behavior theory and conditioning. New Haven: Yale Univ.
Press, 1956.

SPENCE, K. W. A theory of emotionally based drive (D) and its relation to performance in simple learning situations. Amer. Psychologist, 1958, 13, $131-141$.

TAYLOR, Janet A. A personality scale of manifest anxiety. $J$. abnorm. soc. Psychol, 1953, 48, 285-290.

TECCE, J. J. \& HAPP, S. J. Effects of shock-arousal on a card-sorting test of color-word interferences. Percept. mot. Skills, 1964, 19, 905-906.

WRIGHT, J. H., GESCHEIDER, G. A., \& BATTIG, W. F. Performance on a motor learning task as related to MAS scores. Percept. mot. Skills, 1963, 16,368 . 